\title{
Peculiarities of weather and snow accumulation conditions in Moscow region in winter period 2019/2020
}

\author{
Denis Frolov,** \\ ${ }^{1}$ Lomonosov Moscow State University, 119991, Leninskie gory, 1, Moscow, Russia
}

\begin{abstract}
The study of weather and snow accumulation conditions is important because for example on basis of knowledge on temperature regime and accumulation peculiarities of snow cover the ground freezing depth calculations are performed. So the results of study of peculiarities of weather and snow accumulation conditions in Moscow region for winter period 2019/2020 are presented in the paper. The comparison of these data for this winter period with the previous winter periods and the long-term averaged values is also done.
\end{abstract}

\section{Introduction}

As a reason of anomalous warn winter 2019/2020 in Russia, as well as in Europe and USA, is considered non-typical situation in Arctic, where the extremely stable area of low pressure in the vicinity of North Pole was present and which does not let the cold air masses to move away from its borders. Such situation lead to the consequences that on the most of the territory of Russia, USA, Northern Europe and Eastern Canada the temperature of winter months was on few degrees less than usual (fig. 1).

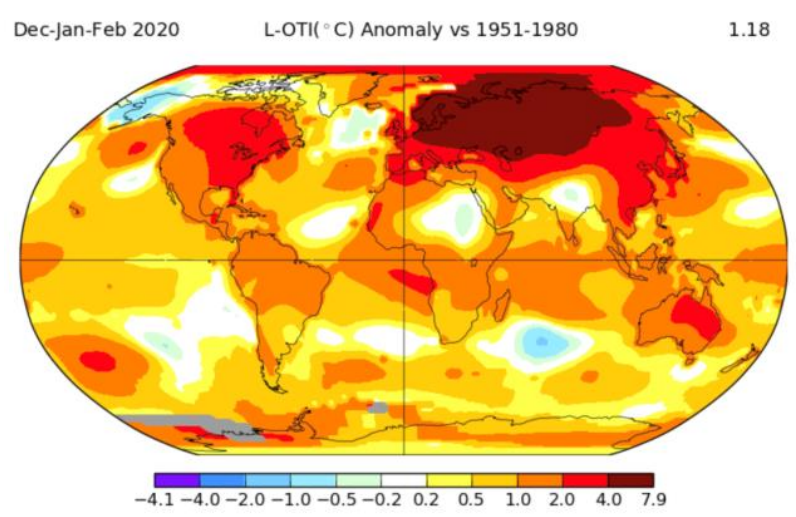

Fig. 1. Anomaly of air temperature in winter period of 2019/2020 in comparison with long-term averaged values of 1951-1980.

${ }^{*}$ Corresponding author: denisfrolovm@mail.ru 


\section{Material and methods}

In our study, according to the VDNKh weather station data $[1,2]$, the air temperature in Moscow in November of the winter period $2019 / 2020$ was $1.8^{\circ} \mathrm{C}$, with an average norm for 1981-2010 value $-1.2^{\circ} \mathrm{C}$. In December, it was $0.8^{\circ} \mathrm{C}$ (with an average norm of $-5.2^{\circ}$ $\mathrm{C}$ ), in January $0.1^{\circ} \mathrm{C}$ (with $-6.5^{\circ} \mathrm{C}$ ), in February $-0.3^{\circ} \mathrm{C}$ (with $-6.7^{\circ} \mathrm{C}$ ) and in March 3.7 ${ }^{\circ} \mathrm{C}$ (with $-1.0^{\circ} \mathrm{C}$ ) (Fig. 2).

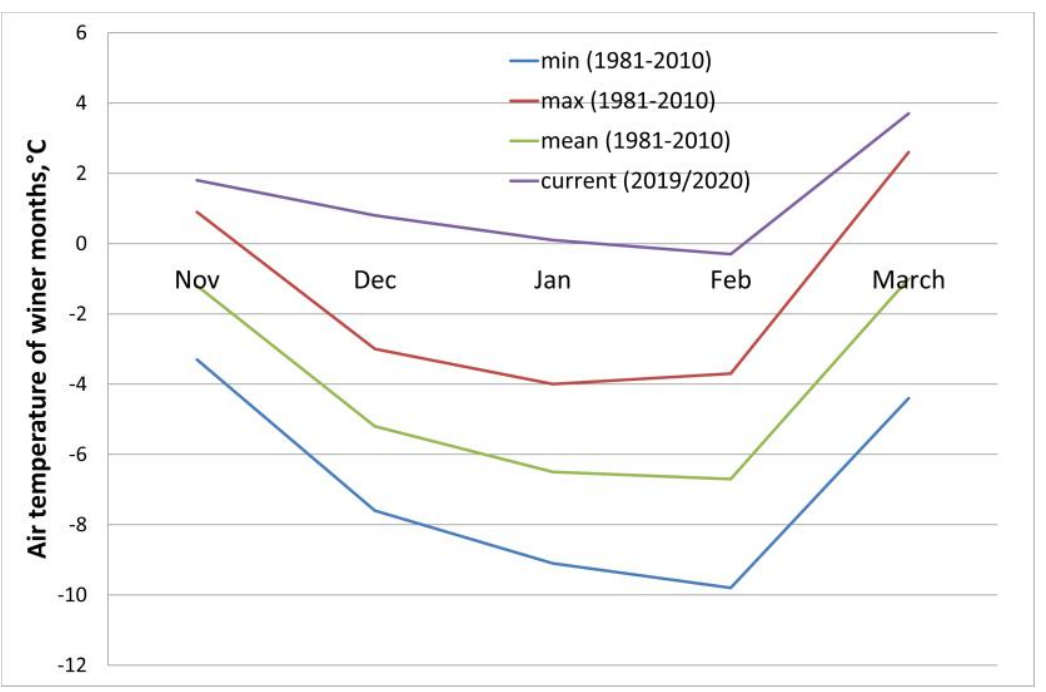

Fig. 2. Mean values of air temperature in the winter months of 2019/2020 and average, maximum and minimum monthly values for 1981-2010.

The amount of precipitation according to the VDNKh weather station [1, 2] in Moscow in the winter season (November-March) of 2019/2020 was slightly less than the norm (1981-2010). In November 2019 it was $35 \mathrm{~mm}$ of precipitation with an average norm for 1981-2010 $55 \mathrm{~mm}$. In December it was $33 \mathrm{~mm}$ with an average norm of $52 \mathrm{~mm}$, in January $55 \mathrm{~mm}$ with an average norm of $52 \mathrm{~mm}$, in February $40 \mathrm{~mm}$ with an average norm of 41 $\mathrm{mm}$ and in March $45 \mathrm{~mm}$ with an average norm of $35 \mathrm{~mm}$ (Fig. 3).

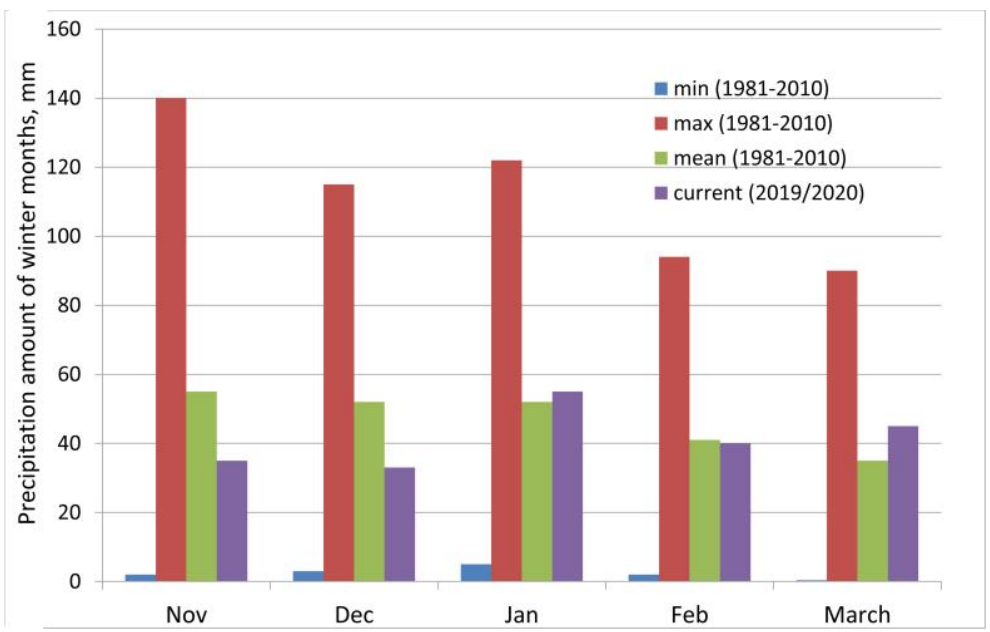

Fig. 3. Precipitation amounts in the winter months of 2019/2020 and average, maximum and minimum monthly values for 1981-2010. 
Due to extremely warm weather the onset of snow cover, in particular in Moscow and the Moscow Region in the winter season 2019/2020 finally occurred only on January 23 (although it was also present since December 30 to January 18), and it was constantly exposed to thaws, and its thickness did not exceed $11 \mathrm{~cm}$ (Fig. 4). These values are recordbreaking, since only in the winter of 2006/2007, according to the data of the VDNKh weather station, the onset of snow cover was only on January 21 and in the winter of 2013/14 the maximum snow cover thickness for the season reached only $15 \mathrm{~cm}$. In the winter of 2018/19, the maximum snow cover thickness for the season reached $49 \mathrm{~cm}$ (Fig. $5)$.

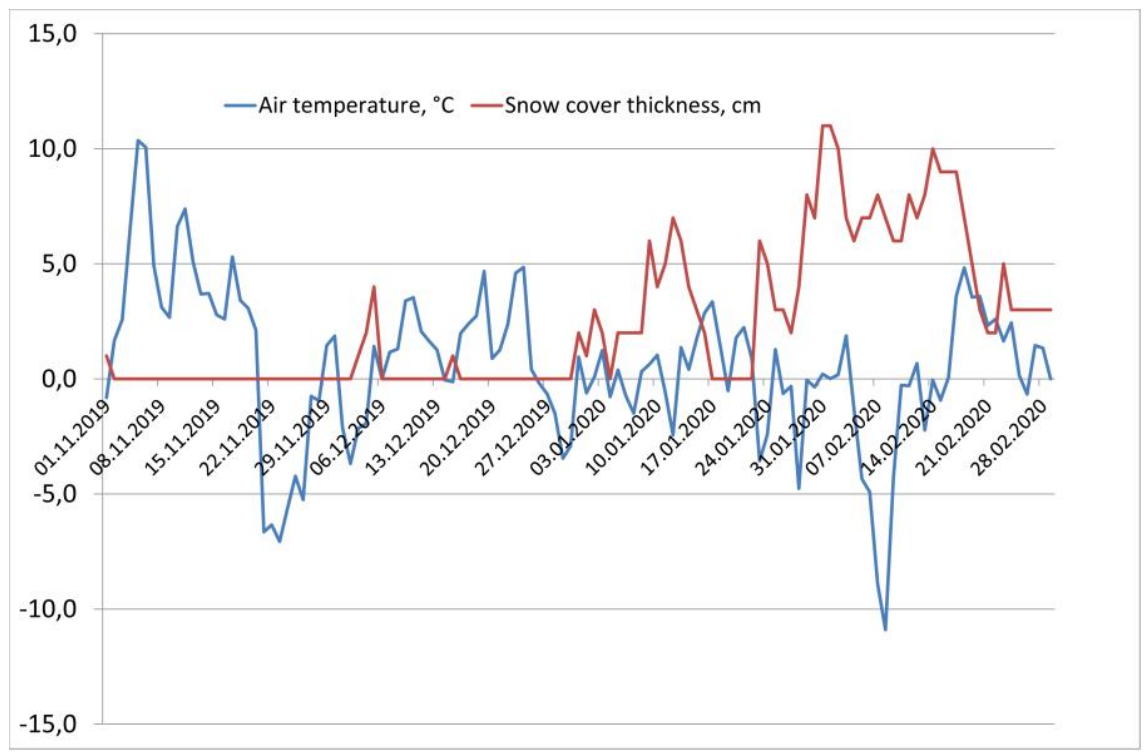

Fig. 4. Variations of air temperature and snow cover thickness of the 2019/2020 winter period.

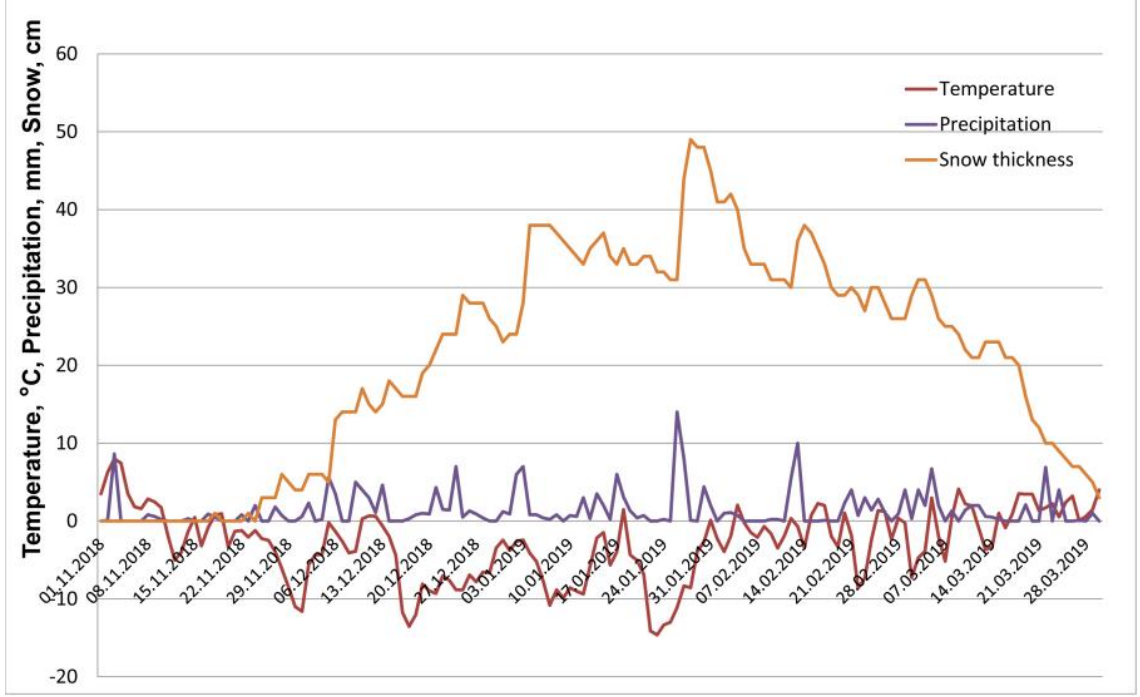

Fig. 5. Variations of air temperature, precipitation, and snow thickness for the winter period 2018/2019 in Moscow. 


\section{Results and discussion}

Considered in this way winter period (November-March) of 2019/2020 in Moscow had the air temperature of $1.2^{\circ} \mathrm{C}$, that is, it was $5.4^{\circ} \mathrm{C}$ higher than the average for $1981-2010$. In the previous winter periods (November-March) of 2018/19 and 2017/18, the air temperature in Moscow was only $1.1^{\circ} \mathrm{C}$ and $0.6^{\circ} \mathrm{C}$ higher than the average value of 1981 2010. Thus, the current winter period 2019/2020 (November to March) occurred to be a record (Fig. 6).

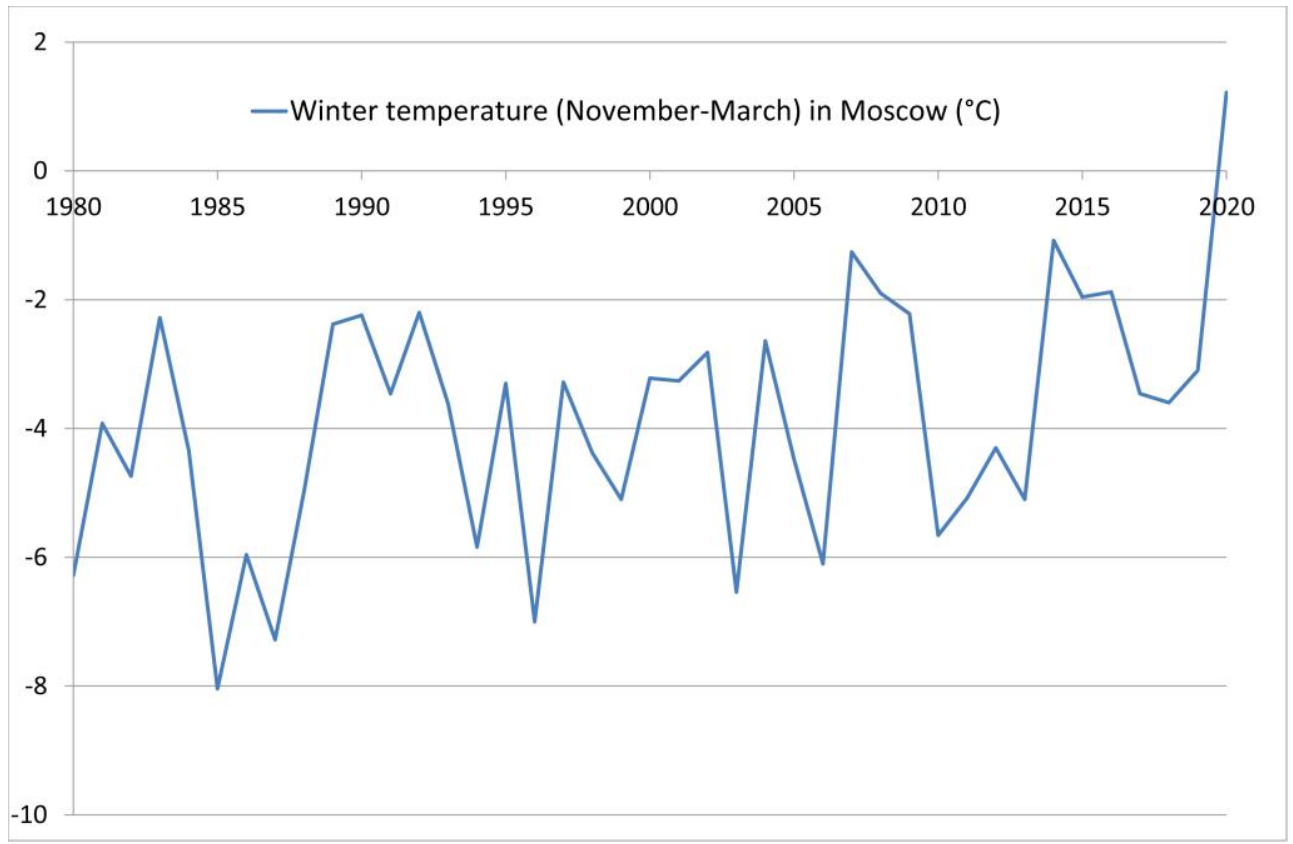

Fig. 6. Mean values of air temperature in winter periods of 1980-2020 in Moscow.

The work was performed in a frame and under support of state topic «Mapping, modelling and assessment of risk of hazardous natural processes» AAAA-A16-116032810093-2.

\section{References}

1. O.N. Bulygina, V.M. Veselov, V.N. Razuvaev T.M. Alexandrova, The description of the array of term data on the main meteorological parameters at stations in Russia, http://meteo.ru/data/163-basic-parameters\#

2. O.N. Bulygina, V.N. Razuvaev, T.M. Alexandrova, The description of the data set of daily air temperature and precipitation at meteorological stations in Russia and the former USSR. (TTTR) (2008). http://meteo.ru/data/162-temperature-precipitation

3. D.M. Frolov, Environmental dynamics and global climate change 10(2) (2019). DOI:10.17816/edgec21203

4. D.M. Frolov, IOP Conference Series: Earth and Environmental Science 386, 1-7. (2019) DOI: 10.1088/1755-1315/386/1/012033

5. D.M. Frolov, Lecture Notes in Civil Engineering 49, 3-8 (Springer, Singapore, 2020). DOI 10.1007/978-981-15-0450-1_1 
6. V.N. Golubev, M.N. Petrushina, D.M. Frolov, Annals of Glaciology 49, 179-186 (2008) 